\title{
Intestinal lactobacilli and the DC-SIGN gene for their recognition by dendritic cells play a role in the aetiology of allergic manifestations.
}

Citation for published version (APA):

Penders, J., Thijs, C. T. M., Mommers, M. A. H., Stobberingh, E. E., Dompeling, E., Reijmerink, N. E., van den Brandt, P. A., Kerkhof, M., Koppelman, G. H., \& Postma, D. S. (2010). Intestinal lactobacilli and the DC-SIGN gene for their recognition by dendritic cells play a role in the aetiology of allergic manifestations. Microbiology, 156(PT11), 3298-3305. https://doi.org/10.1099/mic.0.042069-0

Document status and date:

Published: 01/01/2010

DOI:

10.1099/mic.0.042069-0

Document Version:

Publisher's PDF, also known as Version of record

Document license:

Taverne

Please check the document version of this publication:

- A submitted manuscript is the version of the article upon submission and before peer-review. There can be important differences between the submitted version and the official published version of record.

People interested in the research are advised to contact the author for the final version of the publication, or visit the DOI to the publisher's website.

- The final author version and the galley proof are versions of the publication after peer review.

- The final published version features the final layout of the paper including the volume, issue and page numbers.

Link to publication

\footnotetext{
General rights rights.

- You may freely distribute the URL identifying the publication in the public portal. please follow below link for the End User Agreement:

www.umlib.nl/taverne-license

Take down policy

If you believe that this document breaches copyright please contact us at:

repository@maastrichtuniversity.nl

providing details and we will investigate your claim.
}

Copyright and moral rights for the publications made accessible in the public portal are retained by the authors and/or other copyright owners and it is a condition of accessing publications that users recognise and abide by the legal requirements associated with these

- Users may download and print one copy of any publication from the public portal for the purpose of private study or research.

- You may not further distribute the material or use it for any profit-making activity or commercial gain

If the publication is distributed under the terms of Article $25 \mathrm{fa}$ of the Dutch Copyright Act, indicated by the "Taverne" license above, 
Correspondence John Penders j.penders@mumc.nl

Received 31 May 2010

Revised 10 August 2010

Accepted 2 September 2010

\section{Intestinal lactobacilli and the DC-S/GN gene for their recognition by dendritic cells play a role in the aetiology of allergic manifestations}

John Penders, ${ }^{1,2}$ Carel Thijs, ${ }^{2}$ Monique Mommers, ${ }^{2}$ Ellen E. Stobberingh, ${ }^{1}$ Edward Dompeling, ${ }^{3}$ Naomi E. Reijmerink, ${ }^{4,5}$ Piet A. van den Brandt, ${ }^{6}$ Marjan Kerkhof, ${ }^{7}$ Gerard H. Koppelman ${ }^{8}$ and Dirkje S. Postma ${ }^{4}$

\author{
${ }^{1}$ Department of Medical Microbiology, Care and Public Health Research Institute (Caphri) \\ Maastricht University Medical Centre, 6202 AZ Maastricht, The Netherlands \\ ${ }^{2}$ Department of Epidemiology, Care and Public Health Research Institute (Caphri), \\ Maastricht University, Maastricht, The Netherlands
}

${ }^{3}$ Department of Pediatric Pulmonology, Maastricht University Medical Centre, Maastricht, The Netherlands

${ }^{4}$ Department of Pulmonology, University Medical Center Groningen, University of Groningen, Groningen, The Netherlands

${ }^{5}$ Beatrix Children's Hospital, University Medical Center Groningen, University of Groningen, Groningen, The Netherlands

${ }^{6}$ Department of Epidemiology, Research Institute Growth and Development (GROW), Maastricht University, Maastricht, The Netherlands

${ }^{7}$ Department of Epidemiology, University Medical Center Groningen, University of Groningen, Groningen, Groningen, The Netherlands

${ }^{8}$ Department of Pediatric Pulmonology and Pediatric Allergology, Beatrix Children's Hospital, University Medical Center Groningen, University of Groningen, Groningen, The Netherlands

Diminished exposure to harmless micro-organisms, such as lactobacilli, has been suggested to play a role in the increased prevalence of allergic disorders in Westernized communities. The development of allergies depends on both environmental factors and genetic variations, including polymorphisms in genes encoding pattern recognition receptors. The present study examines the effects of both colonization with specific Lactobacillus species and genetic variations in DC-SIGN, a pattern recognition receptor on dendritic cells that recognizes lactobacilli, on the development of atopic dermatitis (AD) and sensitization in infancy. Within the KOALA Birth Cohort Study, faecal samples of 681 one-month-old infants were collected and quantitatively screened for five Lactobacillus species: L. casei, L. paracasei, L. rhamnosus, L. acidophilus and L. reuteri. Eleven haplotype-tagging polymorphisms in the DC-SIGN gene were genotyped in these children. Allergic outcomes were a clinical diagnosis of $A D$ and sensitization (specific lgE) at age 2 years. $L$. rhamnosus (31.5\%), $L$. paracasei $(31.3 \%)$ and $L$. acidophilus (14.4\%) were frequently detected in the faecal samples of one-month-old infants, whereas $L$. casei $(2.5 \%)$ and $L$. reuteri $(<1 \%)$ were rare. Colonization with $L$. paracasei decreased the risk of AD significantly (odds ratio $0.57,95 \%$ confidence interval $0.32-$ 0.99), whereas effects of $L$. acidophilus were of borderline statistical significance $(0.46,0.20-1.04)$. Two DC-SIGN polymorphisms, rs 11465413 and rs8112555, were statistically significantly associated with atopic sensitization. The present study supports the 'old friends' hypothesis suggesting that certain health-beneficial micro-organisms protect us from developing allergies and that these protective effects are species-dependent. Firm conclusions on the potential interaction between lactobacillus colonization and genetic variations in DC-SIGN in association with the development of allergic disorders cannot be drawn, given the limited power of our study. Therefore, incorporation of consecutive faecal sampling in newly started (birth) cohort studies would be a first requisite to further increase our understanding of host-microbial interactions in health and disease. 


\section{INTRODUCTION}

The 'old friends' hypothesis is one of the most popular explanations for the increase in prevalence of asthma and allergies in the past decades. It implies that the increase in allergic (atopic) disorders in Westernized communities is (partly) explained by diminished exposure to harmless micro-organisms ('old friends') like lactobacilli (Rook et al., 2004; Rook \& Brunet, 2005). These micro-organisms are thought to prime immune regulation. Particularly, the modulation of antigen-presenting cell function by these micro-organisms and consequently the induction of regulatory $\mathrm{T}\left(\mathrm{T}_{\text {reg }}\right)$ cells are considered important (Boirivant \& Strober, 2007; Rook \& Brunet, 2005). Dendritic cells (DCs) are antigen-presenting cells that play an essential role in mucosal tolerance. Depending on the microbial stimulus encountered, DCs secrete cytokines that dictate specific differentiation of unprimed, naïve $\mathrm{CD}^{+} \mathrm{T}$ cells toward Th1, Th2, Th17 or $\mathrm{T}_{\text {reg }}$ cell responses (Geijtenbeek et al., 2009; Mohamadzadeh et al., 2005).

Epidemiological evidence for a protective effect of indigenous lactobacilli on allergic disorders is inconsistent. The first study comparing intestinal microbiota of 2 year-old children with and without atopic dermatitis (AD) showed a lower prevalence of lactobacilli in the faeces of children with the disease (Björkstén et al., 1999). Perturbation in the gut microbiota of allergic children was confirmed in many subsequent studies, but none of these studies showed differences in the prevalence of intestinal lactobacilli (Penders et al., 2007a). The quantification of lactobacilli within these studies was limited to the genus level. As different species of lactobacilli induce distinct and even opposing immune responses (Christensen et al., 2002), the potential species-specific effects of lactobacilli in the aetiology of allergic disorders may thus have been overlooked. Indeed a recent study that differentiated between group I and II lactobacilli reported that children who developed allergy were significantly less colonized with group I lactobacilli (L. rhamnosus, L. paracasei and $L$. casei) during their first months of life (Sjögren et al., 2009).

However, the development of allergic diseases depends not only on environmental factors (like microbial stimulation) but also on genetic factors. Genes involved in microbial recognition, binding and subsequent immune signalling may be important candidates in this respect. The C-type lectin receptor DC-specific ICAM-3-grabbing non-integrin (DCSIGN) is of special interest regarding the recognition and binding of Lactobacillus species. Smits et al. (2005) showed that L. reuteri and L. casei, but not L. plantarum, bind to DCSIGN and prime monocyte-derived DCs to drive the development of IL-10-producing $\mathrm{T}_{\text {reg }}$ cells. Recently, it was demonstrated that L. acidophilus NCFM (North Carolina Food Microbiology) attaches to DCs and induces a concentration-dependent production of IL-10 and low IL12p70. It was further shown that the cellular contacts of DCs and L. acidophilus involve a specific interaction between
DC-SIGN and surface layer protein A of this species (Konstantinov et al., 2008).

Genetic variations in the DC-SIGN receptor have been shown to influence the susceptibility to several infectious agents such as Mycobacterium tuberculosis (Selvaraj et al., 2009; Vannberg et al., 2008), human immunodeficiency virus-1 (Liu et al., 2004; Martin et al., 2004; Selvaraj et al., 2009) and dengue virus (Sakuntabhai et al., 2005). To our knowledge, no studies have so far examined variations in $D C-S I G N$ in association with allergic diseases.

To gain more insight into the species-specific effects of indigenous lactobacilli on the aetiology of allergic diseases, we studied the association between colonization with specific Lactobacillus species in early infancy and the development of $\mathrm{AD}$ and allergic sensitization in the first 2 years of life. Furthermore, we assessed effects of genetic variations in $D C$ SIGN on the development of these atopic outcomes.

\section{METHODS}

Design. This study was conducted within the KOALA Birth Cohort Study, a prospective cohort in the Netherlands, described in detail elsewhere (Kummeling et al., 2005). Briefly, 2834 pregnant women were recruited at 34 weeks of gestation. During pregnancy and early childhood, data on perinatal determinants of the child's health as well as on hygiene, infections, nutrition, child rearing and other lifestyle characteristics were collected for all members of the cohort by repeated questionnaires at 34 weeks of gestation and 3, 7, 12 and 24 months post-partum. The study was approved by the medical ethics committee of Maastricht University. Written informed parental consent was obtained for all participants.

Recruitment of the subcohort. This study investigated all children for whom both a faecal sample, at age 1 month, and a buccal swab sample were available.

All participating parents were asked to provide a buccal swab sample of their child for genotyping, whereas only those participants recruited from January 2002 onwards were asked to consent to sample their child's faeces. After exclusion of premature infants, infants receiving antimicrobial agents during their first month of life, or those having insufficient or no faeces $(<1 \mathrm{~g})$ collections between the ages of 3 and 6 weeks post-partum, and infants without faeces questionnaires, 681 children were eligible for analyses.

When the children reached the age of 2 years, the parents of 506 of the 681 children consented to a home visit for a physical examination of the child for $\mathrm{AD}$ and the collection of venous blood samples to determine specific and total IgE levels.

Faecal microbiota composition. The collection and processing of faecal samples has been described in detail elsewhere (Penders et al., 2007b). Briefly, parents collected a faecal sample by placing a sanitary napkin in the diaper (to prevent absorption of the faeces by the diaper), collected the faeces out of the napkin into the collection tube and sent it immediately to our laboratory by post. At the laboratory faecal samples were diluted tenfold in peptone-water (Oxoid CM0009) containing $20 \%(\mathrm{v} / \mathrm{v})$ glycerol (Merck) and stored at $-20{ }^{\circ} \mathrm{C}$ until analysis. DNA was extracted by a combination of beadbeating and the QIAamp DNA Stool Mini kit. For the present study, faecal samples were subjected to real-time PCRs for the enumeration of total lactobacilli, L. casei, L. paracasei, L. reuteri, L. rhamnosus and L. acidophilus. 
L. paracasei, L. acidophilus and L. rhamnosus were selected because of their relatively high prevalence in this age group compared to other Lactobacillus species (Ahrné et al., 2005; Haarman \& Knol, 2006; Mitsou et al., 2008; Savino et al., 2005). L. casei and L. reuteri were less prevalent in these studies, but were additionally selected because of their proven interaction with DC-SIGN (Smits et al., 2005).

For the quantitative detection of L. reuteri, L. casei and L. paracasei, 5'nuclease assays were used as described by Haarman \& Knol (2006) with slight modifications in primer and probe concentrations. Briefly, amplifications were conducted in a total volume of $25 \mu \mathrm{l}$, containing $1 \times$ TaqMan Universal PCR Master Mix (Applied Biosystems), $300 \mathrm{nM}$ of both primers, $100 \mathrm{nM}$ TaqMan MGB-probe, and $2 \mu \mathrm{l}$ purified target DNA. The amplification $\left(2 \mathrm{~min}\right.$ at $50{ }^{\circ} \mathrm{C}, 10 \mathrm{~min}$ at $95{ }^{\circ} \mathrm{C}$, followed by 42 cycles of $15 \mathrm{~s}$ at $95{ }^{\circ} \mathrm{C}$ and $1 \mathrm{~min}$ at $60{ }^{\circ} \mathrm{C}$ ) and detection were conducted with the ABI Prism 7000 sequence detection system.

For the quantification of L. acidophilus, L. rhamnosus and total lactobacilli, real-time detection of PCR products was conducted with SYBR Green I (primers listed in Table 1). For L. acidophilus and L. rhamnosus, amplifications were conducted in a total volume of $25 \mu \mathrm{l}$, containing $1 \times$ iQ SYBR Green Supermix (Bio-Rad), $2 \mu$ purified target DNA and $100 \mathrm{nM}$ of both primers for L. rhamnosus or $300 \mathrm{nM}$ of both primers for L. acidophilus. The amplification $\left(5 \mathrm{~min}\right.$ at $95{ }^{\circ} \mathrm{C}$, followed by 45 cycles of denaturation at $95{ }^{\circ} \mathrm{C}$ for $15 \mathrm{~s}$, binding and extension for $1 \mathrm{~min}$ at $62{ }^{\circ} \mathrm{C}$ for $L$. rhamnosus or at $60{ }^{\circ} \mathrm{C}$ for $L$. acidophilus) and detection were conducted with the MyiQ Singlecolour real-time PCR Detection System (Bio-Rad). For total lactobacilli, amplifications were conducted in a total volume of $25 \mu$, containing $1 \times$ iQ SYBR Green Supermix (Bio-Rad), $5 \mu l$ purified target DNA and $500 \mathrm{nM}$ of both primers. The amplification was conducted as follows: $5 \mathrm{~min}$ at $95{ }^{\circ} \mathrm{C}$, followed by 35 cycles consisting of $15 \mathrm{~s}$ at $95{ }^{\circ} \mathrm{C}, 20 \mathrm{~s}$ at $58{ }^{\circ} \mathrm{C}, 45 \mathrm{~s}$ at $72{ }^{\circ} \mathrm{C}$, with a final extension step at $72{ }^{\circ} \mathrm{C}$ for $5 \mathrm{~min}$. Following amplification, melt curve analysis was performed from 60 to $95{ }^{\circ} \mathrm{C}$ using increments of $0.5{ }^{\circ} \mathrm{C}$ per $10 \mathrm{~s}$.

Samples were considered to be positive when threshold cycle $\left(C_{\mathrm{t}}\right)$ values were below 35 for total lactobacilli and below 42 for the species-specific PCRs .
Measurement of infants' specific IgE. Venous blood samples were collected from the infants during a home visit at 2 years post-partum. They were analysed for specific IgE against hen's eggs, cow's milk, peanuts, birch, grass pollen, cat, dog and house dust mite using a radioallergosorbent test (RAST) as described earlier (Aalberse et al., 1981). The detection limit for specific IgE was $0.10 \mathrm{IU} \mathrm{ml}^{-1}$.

Definition of atopic dermatitis (AD) and sensitization. Children were defined as having AD according to the UK Working Party (UKWP) criteria (Williams et al., 1994) as determined by a trained research nurse during the home visit at the age of 2 years. The presence of $\mathrm{AD}$ was diagnosed from the presence of four clinical symptoms: 1, presence of itchy rash; 2 , history of flexural dermatitis; 3 , visible flexural dermatitis; and 4 , onset before the age of 2 years. As described previously (Penders et al., 2007b), infants with a UK-WP probability score of $\mathrm{AD}>90 \%$ were regarded as having $\mathrm{AD}$.

Infants were classified as having allergic sensitization when serum IgE levels were $>0.3 \mathrm{IU} \mathrm{ml}^{-1}$ for one or more of the tested food or inhalant allergens.

DNA collection and processing, SNP selection and genotyping. Parents were asked to collect buccal swabs, as source of DNA, from their children. Genomic DNA was extracted from these swabs by standard methods (Sambrook \& Russell, 2001). DNA was amplified by using REPLI-g UltraFast technology (Qiagen).

Haplotype-tagging SNPs were selected from the publicly available database on the Innate Immunity website (Lazarus et al., 2002). Genotyping was performed by competitive allele-specific PCR using KASPar genotyping chemistry, performed under contract by KBiosciences with extensive quality control as described previously (Bottema et al., 2008).

Statistical analysis. The prevalence of $\mathrm{AD}$ and allergic sensitization was calculated according to colonization with the specific Lactobacillus species. $\chi^{2}$ tests were used to test for differences in the prevalence of the atopic outcomes between colonized and uncolonized subjects.

Table 1. Primers and probes used in this study

\begin{tabular}{|c|c|c|c|c|}
\hline Target organism (amplicon size) & Primer/probe & Sequence $\left(5^{\prime}-3^{\prime}\right)$ & $T_{\mathrm{m}}\left({ }^{\circ} \mathrm{C}\right)$ & Reference \\
\hline \multirow[t]{3}{*}{ Lactobacillus reuteri (93 bp) } & Forward primer & ACCGAGAACACCGCGTTATTT & 59 & $\begin{array}{l}\text { Haarman \& Knol } \\
(2006)\end{array}$ \\
\hline & Reverse primer & САТАACTTAACСТАAАCAATCAAAGATTGTCT & 59 & \\
\hline & Probe & 6-FAM-ATCGCTAACTCAATTAAT-MGBNFQ & 69 & \\
\hline \multirow[t]{2}{*}{ Lactobacillus acidophilus (124 bp) } & Forward primer & GATCGCATGATCAGCTTATA & 52 & Furet et al. (2004) \\
\hline & Reverse primer & AGTCTCTCAACTCGGCTATG & 53 & \\
\hline \multirow[t]{2}{*}{ Lactobacillus rhamnosus (116 bp) } & Forward primer & TGCTTGCATCTTGATTTAATTTTG & 52 & Byun et al. (2004) \\
\hline & Reverse primer & GGTTCTTGGATYTATGCGGTATTAG & 54 & \\
\hline \multirow[t]{3}{*}{ Lactobacillus paracasei (80 bp) } & Forward primer & ACATCAGTGTATTGCTTGTCAGTGAATAC & 60 & $\begin{array}{l}\text { Haarman \& Knol } \\
\text { (2006) }\end{array}$ \\
\hline & Reverse primer & CCTGCGGGTACTGAGATGTTTC & 60 & \\
\hline & Probe & 6-FAM- TGCCGCCGGCCAG-MGBNFQ & 70 & \\
\hline \multirow[t]{3}{*}{ Lactobacillus casei (132 bp) } & Forward primer & CTATAAGTAAGCTTTGATCCGGAGATTT & 59 & $\begin{array}{l}\text { Haarman \& Knol } \\
\text { (2006) }\end{array}$ \\
\hline & Reverse primer & CTTCCTGCGGGTACTGAGATGT & 59 & \\
\hline & Probe & 6-FAM-ACAAGCTATGAATTCACTTGC-MGBNFQ & 70 & \\
\hline \multirow[t]{2}{*}{ Lactobacillus spp. (341 bp) } & Forward primer & AGCAGTAGGGAATCTTCCA & 59 & $\begin{array}{l}\text { Rinttilä et al. } \\
\text { (2004) }\end{array}$ \\
\hline & Reverse primer & CACCGCTACACATGGAG & 59 & \\
\hline
\end{tabular}


Linkage disequilibrium (LD) was calculated using Haploview 4.1 (http://www.broad.mit.edu/mpg/haploview), by determining $D^{\prime}$ and $r^{2}$ values. Genotype distribution was tested for deviations $(P<0.05)$ from Hardy-Weinberg equilibrium using $\chi^{2}$ analyses.

We used $\chi^{2}$ tests to analyse whether DC-SIGN SNPs were associated with $\mathrm{AD}$ and allergic sensitization by using a co-dominant model.

Unadjusted and adjusted odds ratios (ORs) and 95\% confidence intervals for the association between Lactobacillus species colonization and atopic outcomes according to the different genotypes were calculated by means of logistic regression. The adjusted regression models included the following potential confounders: 1 , parental atopic history, defined as self-reported doctor's diagnosed eczema, hay fever, asthma, pet and/or house dust mite allergy (both parents non-atopic; at least one parent atopic); 2, siblings atopic history, defined as parentally reported doctor's diagnosed food allergy, eczema, hay fever, asthma, pet and/or house dust mite allergy (no siblings; $\geqslant 1$ siblings, all noneatopic; or $\geqslant 1$ siblings, at least one atopic); 3 , age at collection of faecal sample (age in days); 4 , infant's sex (boy; girl); 5 , pet exposure at home (no pet exposure; only cat exposure; only dog exposure; only other furry pet exposure; combination of cat, $\operatorname{dog}$ and/or other furry pet exposure); 6, recruitment group (alternative; conventional) (Kummeling et al., 2005).

To test whether the effect of Lactobacillus species was modified by host genotype, an interaction term of genotype and Lactobacillus species colonization was included in the logistic regression models and compared to the models without the interaction terms using the likelihood ratio test. All analyses were performed using SPSS 15.0 statistical software and results were considered statistically significant at $P<0.05$. To control for multiple testing, we calculated the false discovery rate (FDR) for the tests for interaction (based on 33 tests for interaction per outcome) according to Benjamini \& Hochberg (1995). The $P$-values were tested for significance at a FDR ( $q$-value) of 0.05 .

\section{RESULTS}

\section{Intestinal colonization by lactobacilli and allergic manifestations}

The prevalence of the Lactobacillus species in the current study population was as follows: $L$. rhamnosus $31.5 \%, L$. paracasei $31.3 \%$, L. acidophilus $14.4 \%$, L. casei $2.5 \%$ and $L$. reuteri $<1 \%$. Because of the low prevalence of $L$. case $i$ and $L$. reuteri in our population, these bacteria were not taken into account for further analysis.

Information on $\mathrm{AD}$ was available for all 506 children that were visited at home, whereas information on atopic sensitization was available for 492 children.

The risk of $\mathrm{AD}$ at age 2 years was significantly lower in children who were colonized with $L$. paracasei [odds ratio (OR) $0.57,95 \%$ confidence interval (CI) $0.32-0.99, P=0.04$ ] compared with those not colonized. For $L$. acidophilus a borderline statistically significant decreased risk of $\mathrm{AD}$ was found (OR 0.46, $95 \%$ CI $0.20-1.04)(P=0.06)$. Neither of these species, nor L. rhamnosus, were however associated with the risk of atopic sensitization (Table 2).

\section{DC-SIGN gene variants}

Eleven DC-SIGN SNPs were genotyped (Table 3), all of which were in Hardy-Weinberg equilibrium. Strong LD,
Table 2. Prevalence of allergic sensitization and $A D$ according to Lactobacillus species colonization

\begin{tabular}{|lcll|}
\hline Lactobacillus & Present? & $\begin{array}{c}\text { Sensitization } \% \\
\text { (cases/total) }\end{array}$ & $\begin{array}{c}\text { AD } \\
\text { (cases/total) }\end{array}$ \\
\hline L. paracasei & No & $28.4(95 / 334)$ & $18.1(62 / 343)$ \\
& Yes & $28.0(44 / 157)$ & $11.1(18 / 162)$ \\
L. rhamnosus & No & $27.3(92 / 337)$ & $15.3(53 / 347)$ \\
& Yes & $30.1(46 / 153)$ & $17.2(27 / 157)$ \\
& & $P=0.53$ & $P=0.58$ \\
L. acidophilus & No & $28.0(116 / 415)$ & $17.1(73 / 426)$ \\
& Yes & $31.2(24 / 77)$ & $8.8(7 / 80)$ \\
& & $P=0.57$ & $P=0.06$ \\
Lactobacillus spp. & No & $28.0(94 / 336)$ & $15.7(54 / 345)$ \\
& Yes & $29.5(46 / 156)$ & $16.1(26 / 161)$ \\
& & $P=0.73$ & $P=0.89$ \\
& & & \\
\hline
\end{tabular}

${ }^{*} \mathrm{AD}$ according to UK Working Party criteria.

with $D^{\prime}$ approaching the value of 1 (Fig. 1), was observed for rs7252229, rs2287886, rs4804803, rs735239, rs735240, rs11465360, rs7359874 and rs4804804.

Table 4 presents the association between these SNPs and the atopic outcomes under study. None of the SNPs were associated with AD. Two SNPs, rs11465413 and rs8112555, were statistically significantly associated with atopic sensitization. Of the children who were heterozygous for rs $11465413,17.9 \%$ were sensitized at the age of 2 years as compared to $30.0 \%$ of the homozygotes for the major allele $(P=0.04)$. Heterozygotes for rs8112555 were also at decreased risk of developing atopic sensitization as

Table 3. Selected DC-SIGN SNPs and minor allele frequencies in the study population

\begin{tabular}{|lccc|}
\hline DC-SIGN SNP & Alleles $^{*}$ & $\begin{array}{c}\text { Minor allele } \\
\text { frequency }\end{array}$ & $\begin{array}{c}\text { P-value } \dagger \text { for } \\
\text { deviation from } \\
\text { Hardy-Weinberg } \\
\text { equilibrium }\end{array}$ \\
\hline rs11465360 & C:A & 0.05 & \\
rs11465413 & T:A & 0.09 & 0.39 \\
rs11465421 & A : C & 0.47 & 0.42 \\
rs2287886 & G:A & 0.36 & 0.35 \\
rs4804803 & A : G & 0.19 & 0.51 \\
rs4804804 & G:A & 0.36 & 0.57 \\
rs7252229 & G:C & 0.13 & 0.41 \\
rs735239 & A : G & 0.34 & 0.96 \\
rs735240 & G:A & 0.44 & 0.86 \\
rs7359874 & A : T & 0.49 & 0.86 \\
rs8112555 & G:A & 0.14 & 0.45 \\
\hline
\end{tabular}

${ }^{\star}$ Minor alleles first.

$\dagger$ As determined by $\chi^{2}$ test. 
(a)

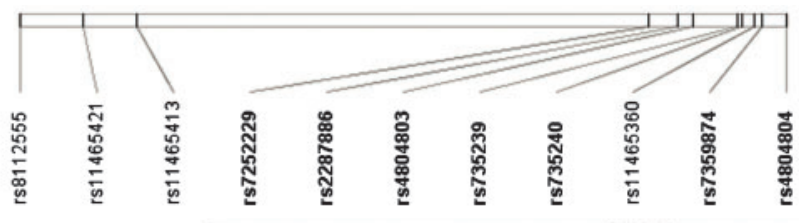

(b)
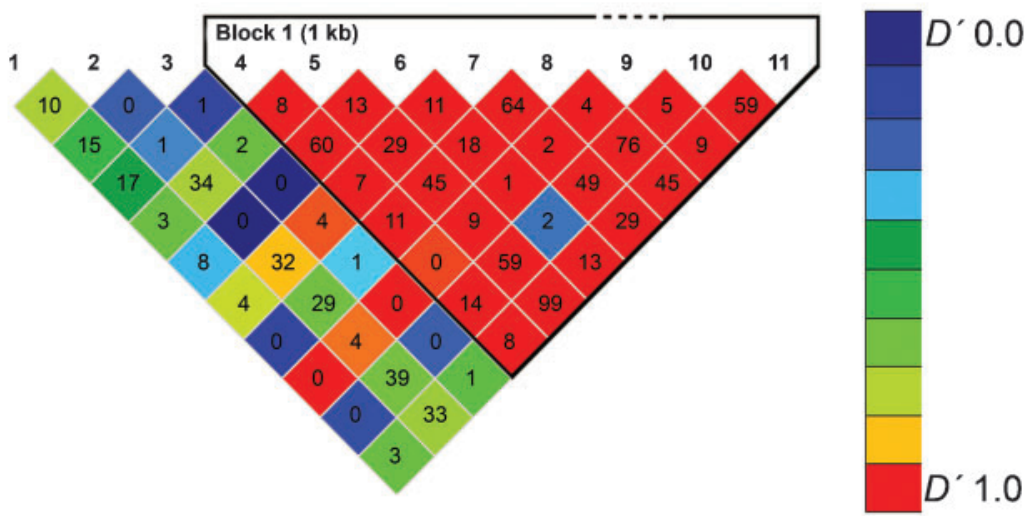

Fig. 1. Position and linkage disequilibrium of the SNPs within DC-SIGN. (a) DC-SIGN is located on chromosome 19 (19p13). Eleven haplotype tagging DC-SIGN SNPs were selected. All SNPs are in Hardy-Weinberg (HW) equilibrium $(P>0.05)$. (b) Pairwise linkage disequilibrium plot according to Haploview 4.1 for DC-SIGN SNPs. $D^{\prime}$ is represented by colour, changing from red $\left(D^{\prime}=1\right)$ to dark blue $\left(D^{\prime}=0\right) . D^{\prime}$ is 1 when no recombination has occurred between two SNPs. The measure of $r^{2}$ is represented by a number ranging from 0 to 100 . When the minor alleles at two SNP positions are always present on the same haplotype, $r^{2}=100$; when the minor alleles are always on separate haplotypes, $r^{2}=0$.

compared to children homozygotic for the major alleles of this SNP $(P=0.03)$.

\section{Gene-environment interaction}

To examine whether the associations between colonization with the Lactobacillus species and atopic outcomes were modified by genetic variations in DC-SIGN, we examined these associations stratified for DC-SIGN genotype, and tested for statistical interaction (test for differences of odds ratios between strata of DC-SIGN genotypes). The only statistically significant interaction $(P$ for interaction $=0.03$ ) was found between L. rhamnosus colonization and rs11465360. L. rhamnosus colonization was associated with an increased risk of $\mathrm{AD}$ in homozygotes for the major allele (CC) (OR 1.63, 0.93-2.84) and with a decreased risk in heterozygotes (CA) (OR 0.17, 0.02-1.35); however, this interaction did not withstand correction for multiple testing.

\section{DISCUSSION}

We examined the effect of common intestinal Lactobacillus species in early infancy and genetic variations in DC-SIGN in association with development of $\mathrm{AD}$ and allergic sensitization in early childhood within the KOALA birth cohort.

Colonization by $L$. acidophilus was associated with a statistically significant decreased risk of $\mathrm{AD}$, whereas effects of $L$. paracasei were of borderline significance. These findings are in agreement with the 'old friends' hypothesis suggesting that certain health-beneficial micro-organisms may protect us from developing allergies and that these effects are species-dependent.

However, we did not find any effect of $L$. acidophilus and $L$. paracasei colonization on atopic sensitization.
No previous observational studies have examined the association of specific Lactobacillus species, but the effects of $L$. paracasei and $L$. acidophilus supplementation on the primary prevention of (atopic) dermatitis have been studied in randomized controlled trials. In agreement with our study, the trial by West et al. (2009) demonstrated that $L$. paracasei supplementation in early infancy reduced the incidence of eczema but did not influence atopic sensitization. Indeed, the role of allergic sensitization in childhood $\mathrm{AD}$ remains far from clear. It is neither a prerequisite nor a uniform cause of the disease (Williams \& Flohr, 2006).

In contrast to the above results, however, $L$. acidophilus (LAVRI-A1) supplementation in high-risk newborns failed to reduce the incidence of eczema as compared to placebo (Taylor et al., 2007).

As a pattern recognition receptor, DC-SIGN interacts with a plethora of, mainly pathogenic, micro-organisms other than lactobacilli (Geijtenbeek et al., 2000). DC-SIGN is organized into three domains: an N-terminal cytoplasmic region, a neck region containing eight repeats of a 23 aa sequence, and a C-terminal C-type lectin domain (Soilleux et al., 2000). The CD209 gene is located on chromosome $19 \mathrm{p} 13.2-3$ and is highly polymorphic.

In the present study, two DC-SIGN SNPs (rs11465413 and rs8112555) were associated with atopic sensitization. Homozygotes for the major allele of these SNPs had a significantly higher risk of sensitization than heterozygous children. Because of the low minor allele frequency of both SNPs, the risk of sensitization in children homozygous for the minor allele could not be examined.

Since this is the first study in which the association between $D C$-SIGN gene variants and atopic disorders has been studied, it would be worthwhile to examine whether these associations could be confirmed in another population. To 
Table 4. Prevalence of allergic sensitization and $A D$ at age 2 years according to $D C-S / G N$ genotype

\begin{tabular}{|c|c|c|c|}
\hline$D C$-SIGN genotype & & $\begin{array}{l}\text { Allergic sensitization } \\
\% \text { (cases/total) }\end{array}$ & $\mathrm{AD} \%$ (cases/total) \\
\hline \multirow[t]{4}{*}{ rs11465360 } & $\mathrm{CC}$ & $27.9(120 / 430)$ & $15.9(70 / 441)$ \\
\hline & CA & $29.3(12 / 41)$ & $20.9(9 / 43)$ \\
\hline & $\mathrm{AA}^{*}$ & $50.0(1 / 2)$ & $0(0 / 2)$ \\
\hline & & $P=0.85$ & $P=0.39$ \\
\hline \multirow[t]{4}{*}{ rs11465413 } & $\mathrm{TT}$ & $30.0(124 / 413)$ & $14.9(63 / 423)$ \\
\hline & TA & $17.9(12 / 67)$ & $19.7(14 / 71)$ \\
\hline & AA & $*(1 / 3)$ & $\star(1 / 3)$ \\
\hline & & $P=0.04$ & $P=0.30$ \\
\hline \multirow[t]{4}{*}{ rs11465421 } & $\mathrm{AA}$ & $29.7(44 / 148)$ & $15.2(23 / 151)$ \\
\hline & $\mathrm{CA}$ & $27.7(62 / 224)$ & $14.6(34 / 233)$ \\
\hline & $\mathrm{CC}$ & $28.3(30 / 106)$ & $18.5(20 / 108)$ \\
\hline & & $P=0.91$ & $P=0.64$ \\
\hline rs2287886 & GG & $27.1(54 / 199)$ & $15.8(32 / 203)$ \\
\hline \multirow[t]{3}{*}{ (CD209 139 C/T) } & GA & $29.0(63 / 217)$ & $16.5(37 / 224)$ \\
\hline & $\mathrm{AA}$ & $29.7(19 / 64)$ & $21.1(8 / 66)$ \\
\hline & & $P=0.88$ & $P=0.69$ \\
\hline rs4804803 & AA & $27.7(88 / 319)$ & $14.9(49 / 328)$ \\
\hline \multirow[t]{3}{*}{ (CD209 336 C/T) } & GA & $29.6(42 / 142)$ & $15.1(22 / 146)$ \\
\hline & GG & $31.8(7 / 22)$ & $31.8(7 / 22)$ \\
\hline & & $P=0.86$ & $P=0.11$ \\
\hline rs4804804 & GG & $27.6(56 / 203)$ & $15.5(32 / 207)$ \\
\hline \multirow{3}{*}{$(C D 2091466 \mathrm{C} / \mathrm{T})$} & GA & $28.2(61 / 216)$ & $17.0(38 / 224)$ \\
\hline & $\mathrm{AA}$ & $29.2(19 / 65)$ & $11.9(8 / 67)$ \\
\hline & & $P=0.97$ & $P=0.61$ \\
\hline rs7252229 & GG & $28.9(105 / 363)$ & $14.2(53 / 373)$ \\
\hline \multirow[t]{3}{*}{$(C D 209216 \mathrm{C} / G)$} & CG & $23.4(25 / 107)$ & $18.9(21 / 111)$ \\
\hline & $\mathrm{CC}$ & $*(5 / 9)$ & $*(5 / 9)$ \\
\hline & & $P=0.26$ & $P=0.23$ \\
\hline rs735239 & $\mathrm{AA}$ & $29.5(62 / 210)$ & $17.5(38 / 217)$ \\
\hline \multirow[t]{3}{*}{$(C D 209871 C / T)$} & GA & $27.6(56 / 203)$ & $13.9(29 / 208)$ \\
\hline & GG & $27.0(17 / 63)$ & $14.1(9 / 64)$ \\
\hline & & $P=0.88$ & $P=0.56$ \\
\hline rs735240 & GG & $30.7(46 / 150)$ & $17.5(27 / 154)$ \\
\hline \multirow[t]{3}{*}{$(C D 209939 \mathrm{C} / \mathrm{T})$} & GA & $27.0(61 / 226)$ & $13.7(32 / 234)$ \\
\hline & $\mathrm{AA}$ & $28.4(27 / 95)$ & $15.5(15 / 97)$ \\
\hline & & $P=0.74$ & $P=0.59$ \\
\hline rs7359874 & $\mathrm{TT}$ & $31.9(38 / 119)$ & $17.9(22 / 123)$ \\
\hline \multirow[t]{3}{*}{$(C D 2091180 \mathrm{~A} / \mathrm{T})$} & TA & $25.6(58 / 227)$ & $14.9(35 / 235)$ \\
\hline & $\mathrm{AA}$ & $30.2(39 / 129)$ & $13.0(17 / 131)$ \\
\hline & & $P=0.40$ & $P=0.55$ \\
\hline rs8112555 & GG & $30.5(110 / 361)$ & $15.9(59 / 371)$ \\
\hline \multirow[t]{3}{*}{$(C D 2097882 \mathrm{C} / \mathrm{T})$} & GA & $19.6(22 / 112)$ & $13.8(16 / 116)$ \\
\hline & $\mathrm{AA}$ & $*(5 / 8)$ & * $(3 / 8)$ \\
\hline & & $P=0.03$ & $P=0.58$ \\
\hline
\end{tabular}

${ }^{*}$ Minor allele homozygotes excluded from $\chi^{2}$ tests analyses because of limited number of subjects.

our knowledge, studies in which our findings could be replicated are currently lacking. It would therefore be of high value if newly conducted birth cohort studies on allergic, but also other, diseases were to incorporate consecutive faecal sampling throughout the first year of life. As well as replication of our findings, this could significantly enhance the possibilities and power to study host-microbial interaction in health and disease by pooling data from such studies. In the current molecular era, incorporation of faecal sampling within such new observational studies can be achieved relatively easily.

Within the present study no statistically significant geneby-environment interactions were found after adjusting for 
multiple testing. This may partly be due to the relatively low number of children with both DNA and faecal samples available, even though this is one of the largest, if not the largest, cohort on gut microbial ecology. Furthermore, the low minor allele frequency of this particular SNP also reduced the power to detect an interaction that could withstand correction for multiple testing. Whether the effects of Lactobacillus species on the development of atopic diseases are modified by genetic variations in $D C$ SIGN can therefore not be answered until sample sizes can be increased significantly by pooling data from new studies.

The present study was limited in the number of Lactobacillus species that were targeted: we only examined five of the 17 Lactobacillus species that can be present in the human gastrointestinal tract (Walter, 2008). However, we do not expect to have missed any species that are commonly found in early infancy. Our results on the Lactobacillus species composition are in agreement with several previous studies which consistently showed that around the age of 1 month $L$. paracasei, L. acidophilus and L. rhamnosus (Ahrné et al., 2005; Haarman \& Knol, 2006; Mitsou et al., 2008; Savino et al., 2005) are among the most prevalent species. In the same studies $L$. reuteri and $L$. casei and several other species were absent or contributed only a tiny amount to the Lactobacillus microbiota of infants (Ahrné et al., 2005; Haarman \& Knol, 2006; Mitsou et al., 2008; Savino et al., 2005).

Another drawback of our study is the availability of only one faecal sample per subject. Caution is therefore due when particular Lactobacillus species are considered as lasting (autochthonous) inhabitants. It has so far not been confirmed that the Lactobacillus species examined in the present study actually form stable populations. Therefore, the presence of these species may only indicate the passage of allochthonous strains. As a consequence, our results may not be directly comparable with results of clinical trials in which continuous exposure to the probiotic microorganism(s) under study during the intervention period is assumed to take place at relevant immune surfaces in the gastrointestinal tract. It is therefore plausible that similar interactions between the host's genotype and probiotics exist and that this could at least partly explain differences in the results of probiotic trials. It would therefore be of interest to study the effects of probiotic trials within specific genetic subgroups. This may also partly resolve inconsistencies between trials in populations with different distributions of genetic variants.

In conclusion, the current study shows a decreased risk of $\mathrm{AD}$ in children colonized by L. acidophilus and L. paracasei and provides evidence that there is an association between two DC-SIGN SNPs and allergic sensitization.

To further increase our understanding of host-microbial interactions in health and disease, the incorporation of consecutive faecal sampling in newly developed (birth) cohort studies would be a first requisite.

\section{ACKNOWLEDGEMENTS}

This study was financially supported by the Netherlands Asthma Foundation (grant number 3.2.07.022) and The Netherlands Organization for Health Research and Development (ZonMw; grant number 912-03-031)

\section{REFERENCES}

Aalberse, R. C., Koshte, V. \& Clemens, J. G. (1981). Immunoglobulin $\mathrm{E}$ antibodies that crossreact with vegetable foods, pollen, and Hymenoptera venom. J Allergy Clin Immunol 68, 356-364.

Ahrné, S., Lonnermark, E., Wold, A. E., Aberg, N., Hesselmar, B., Saalman, R., Strannegard, I. L., Molin, G. \& Adlerberth, I. (2005). Lactobacilli in the intestinal microbiota of Swedish infants. Microbes Infect 7, 1256-1262.

Benjamini, Y. \& Hochberg, Y. (1995). Controlling the false discovery rate: a practical and powerful approach to multiple testing. $J R$ Stat Soc Series B Stat Methodol 57, 289-300.

Björkstén, B., Naaber, P., Sepp, E. \& Mikelsaar, M. (1999). The intestinal microflora in allergic Estonian and Swedish 2-year-old children. Clin Exp Allergy 29, 342-346.

Boirivant, M. \& Strober, W. (2007). The mechanism of action of probiotics. Curr Opin Gastroenterol 23, 679-692.

Bottema, R. W., Reijmerink, N. E., Kerkhof, M., Koppelman, G. H., Stelma, F. F., Gerritsen, J., Thijs, C., Brunekreef, B., van Schayck, C. P. \& Postma, D. S. (2008). Interleukin 13, CD14, pet and tobacco smoke influence atopy in three Dutch cohorts: the allergenic study. Eur Respir J 32, 593-602.

Byun, R., Nadkarni, M. A., Chhour, K. L., Martin, F. E., Jacques, N. A. \& Hunter, N. (2004). Quantitative analysis of diverse Lactobacillus species present in advanced dental caries. J Clin Microbiol 42, 31283136.

Christensen, H. R., Frokiaer, H. \& Pestka, J. J. (2002). Lactobacilli differentially modulate expression of cytokines and maturation surface markers in murine dendritic cells. J Immunol 168, 171-178.

Furet, J. P., Quenee, P. \& Tailliez, P. (2004). Molecular quantification of lactic acid bacteria in fermented milk products using real-time quantitative PCR. Int J Food Microbiol 97, 197-207.

Geijtenbeek, T. B., Torensma, R., van Vliet, S. J., van Duijnhoven, G. C., Adema, G. J., van Kooyk, Y. \& Figdor, C. G. (2000). Identification of DC-SIGN, a novel dendritic cell-specific ICAM-3 receptor that supports primary immune responses. Cell 100, 575-585.

Geijtenbeek, T. B., den Dunnen, J. \& Gringhuis, S. I. (2009). Pathogen recognition by DC-SIGN shapes adaptive immunity. Future Microbiol 4, 879-890.

Haarman, M. \& Knol, J. (2006). Quantitative real-time PCR analysis of fecal Lactobacillus species in infants receiving a prebiotic infant formula. Appl Environ Microbiol 72, 2359-2365.

Konstantinov, S. R., Smidt, H., de Vos, W. M., Bruijns, S. C., Singh, S. K., Valence, F., Molle, D., Lortal, S., Altermann, E. \& other authors (2008). S layer protein of Lactobacillus acidophilus NCFM regulates immature dendritic cell and T cell functions. Proc Natl Acad Sci U S A 105, 19474-19479.

Kummeling, I., Thijs, C., Penders, J., Snijders, B. E., Stelma, F., Reimerink, J., Koopmans, M., Dagnelie, P. C., Huber, M. \& other authors (2005). Etiology of atopy in infancy: the KOALA Birth Cohort Study. Pediatr Allergy Immunol 16, 679-684.

Lazarus, R., Vercelli, D., Palmer, L. J., Klimecki, W. J., Silverman, E. K., Richter, B., Riva, A., Ramoni, M., Martinez, F. D. \& other authors (2002). Single nucleotide polymorphisms in innate immunity genes: 
abundant variation and potential role in complex human disease. Immunol Rev 190, 9-25.

Liu, H., Hwangbo, Y., Holte, S., Lee, J., Wang, C., Kaupp, N., Zhu, H., Celum, C., Corey, L. \& other authors (2004). Analysis of genetic polymorphisms in CCR5, CCR2, stromal cell-derived factor-1, RANTES, and dendritic cell-specific intercellular adhesion molecule-3-grabbing nonintegrin in seronegative individuals repeatedly exposed to HIV-1. J Infect Dis 190, 1055-1058.

Martin, M. P., Lederman, M. M., Hutcheson, H. B., Goedert, J. J., Nelson, G. W., van Kooyk, Y., Detels, R., Buchbinder, S., Hoots, K. \& other authors (2004). Association of DC-SIGN promoter polymorphism with increased risk for parenteral, but not mucosal, acquisition of human immunodeficiency virus type 1 infection. J Virol 78, 14053-14056.

Mitsou, E. K., Kirtzalidou, E., Oikonomou, I., Liosis, G. \& Kyriacou, A. (2008). Fecal microflora of Greek healthy neonates. Anaerobe 14, 94-101.

Mohamadzadeh, M., Olson, S., Kalina, W. V., Ruthel, G., Demmin, G. L., Warfield, K. L., Bavari, S. \& Klaenhammer, T. R. (2005). Lactobacilli activate human dendritic cells that skew T cells toward T helper 1 polarization. Proc Natl Acad Sci U S A 102, 2880-2885.

Penders, J., Stobberingh, E. E., van den Brandt, P. A. \& Thijs, C. (2007a). The role of the intestinal microbiota in the development of atopic disorders. Allergy 62, 1223-1236.

Penders, J., Thijs, C., van den Brandt, P. A., Kummeling, I., Snijders, B. Stelma, F., Adams, H., van Ree, R. \& Stobberingh, E. E. (2007b). Gut microbiota composition and development of atopic manifestations in infancy: the KOALA birth cohort study. Gut 56, 661-667.

Rinttilä, T., Kassinen, A., Malinen, E., Krogius, L. \& Palva, A. (2004). Development of an extensive set of $16 \mathrm{~S}$ rDNA-targeted primers for quantification of pathogenic and indigenous bacteria in faecal samples by real-time PCR. J Appl Microbiol 97, 1166-1177.

Rook, G. A. \& Brunet, L. R. (2005). Microbes, immunoregulation, and the gut. Gut 54, 317-320.

Rook, G. A., Adams, V., Hunt, J., Palmer, R., Martinelli, R. \& Brunet, L. R. (2004). Mycobacteria and other environmental organisms as immunomodulators for immunoregulatory disorders. Springer Semin Immunopathol 25, 237-255.

Sakuntabhai, A., Turbpaiboon, C., Casadémont, I., Chuansumrit, A., Lowhnoo, T., Kajaste-Rudnitski, A., Kalayanarooj, S. M., Tangnararatchakit, K., Tangthawornchaikul, N. \& other authors (2005). A variant in the $C D 209$ promoter is associated with severity of dengue disease. Nat Genet 37, 507-513.

Sambrook, J. \& Russell, D. (2001). Molecular Cloning: a Laboratory Manual, 3rd edn. Cold Spring Harbor, NY: Cold Spring Harbor Laboratory.
Savino, F., Bailo, E., Oggero, R., Tullio, V., Roana, J., Carlone, N., Cuffini, A. M. \& Silvestro, L. (2005). Bacterial counts of intestinal Lactobacillus species in infants with colic. Pediatr Allergy Immunol 16, 72-75.

Selvaraj, P., Alagarasu, K., Swaminathan, S., Harishankar, M. \& Narendran, G. (2009). CD209 gene polymorphisms in South Indian HIV and HIV-TB patients. Infect Genet Evol 9, 256-262.

Sjögren, Y. M., Jenmalm, M. C., Bottcher, M. F., Bjorksten, B. \& Sverremark-Ekstrom, E. (2009). Altered early infant gut microbiota in children developing allergy up to 5 years of age. Clin Exp Allergy 39, 518-526.

Smits, H. H., Engering, A., Van der Kleij, D., de Jong, E. C., Schipper, K., van Capel, T. M., Zaat, B. A., Yazdanbakhsh, M., Wierenga, E. A. \& other authors (2005). Selective probiotic bacteria induce IL-10-producing regulatory $\mathrm{T}$ cells in vitro by modulating dendritic cell function through dendritic cell-specific intercellular adhesion molecule 3-grabbing nonintegrin. J Allergy Clin Immunol 115, 1260-1267.

Soilleux, E. J., Barten, R. \& Trowsdale, J. (2000). DC-SIGN; a related gene, DC-SIGNR; and CD23 form a cluster on 19p13. J Immunol 165, 2937-2942.

Taylor, A. L., Dunstan, J. A. \& Prescott, S. L. (2007). Probiotic supplementation for the first 6 months of life fails to reduce the risk of atopic dermatitis and increases the risk of allergen sensitization in high-risk children: a randomized controlled trial. J Allergy Clin Immunol 119, 184-191.

Vannberg, F. O., Chapman, S. J., Khor, C. C., Tosh, K., Floyd, S., Jackson-Sillah, D., Crampin, A., Sichali, L., Bah, B. \& other authors (2008). CD209 genetic polymorphism and tuberculosis disease. PLoS ONE 3, e1388.

Walter, J. (2008). Ecological role of lactobacilli in the gastrointestinal tract: implications for fundamental and biomedical research. Appl Environ Microbiol 74, 4985-4996.

West, C. E., Hammarstrom, M. L. \& Hernell, O. (2009). Probiotics during weaning reduce the incidence of eczema. Pediatr Allergy Immunol 20, 430-437.

Williams, H. \& Flohr, C. (2006). How epidemiology has challenged 3 prevailing concepts about atopic dermatitis. J Allergy Clin Immunol 118, 209-213.

Williams, H. C., Burney, P. G., Pembroke, A. C. \& Hay, R. J. (1994). The U.K. Working Party's Diagnostic Criteria for Atopic Dermatitis. III. Independent hospital validation. Br J Dermatol 131, 406416.

Edited by: P. W. O'Toole 